\section{Anticyclic Citrullinated Peptide Antibodies in Patients with Rheumatic Diseases other than Rheumatoid Arthritis: Clinical or Pathogenic Significance?}

\section{To the Editor:}

We read with interest about the study by Payet, et al investigating prevalence and discriminatory value of anticyclic citrullinated peptide (anti-CCP) antibodies in patients with rheumatic diseases other than rheumatoid arthritis (RA) ${ }^{1}$. Although several studies have been published aiming to identify the prevalence of anti-CCP in patients with different rheumatic conditions ${ }^{2,3,4}$, Payet's study was performed in a very large patient cohort and represents, therefore, a relevant information source on this topic. The overall prevalence of anti-CCP in the 723 non-RA patients was rather high compared to other studies $^{5,6,7}$, with a very high proportion of patients with connective tissue disease (CTD) with anti-CCP (17.5\%). This allowed the conclusion that, although anti-CCP are rather specific for RA, they are consistently expressed in patients with other rheumatic diseases. However, it should be noted that, unlike previously published studies analyzing anti-CCP prevalence in non-RA disorders, the design of Payet's investigation considered the analysis of sera sent for anti-CCP determination and later evaluation of the diagnosis. Thus a bias, due to inevitable selection of patients with joint involvement, may be supposed. Indeed, the majority of these patients, including subjects with CTD, presented articular manifestations and often, erosive disease.

We performed a similar retrospective study analyzing our anti-CCP database with selection of the last 1500 consecutive serum samples. Diagnoses were known in 948 patients and the anti-CCP positivity was distributed as follows: 420/754 RA (56\%), 5/58 Sjögren's syndrome (SS; $8.6 \%), 1 / 76$ psoriatic arthritis (PsA; 1.3\%), 0/32 systemic lupus erythematosus (SLE), 1/28 systemic sclerosis (SSc; $3.5 \%$ ), with overall prevalence of $3.7 \%$ in non-RA patients. Anti-CCP prevalence in SLE, SS, SSc, and PsA was in line with that extrapolated from an Italian multicenter study comparing the diagnostic value of anti-CCP, antimutated citrullinated vimentin, and antiviral citrullinated peptide $2^{8}$.

The most striking datum of Payet's study was represented by the very high prevalence of anti-CCP in CTD (17.5\% vs $5.1 \%$ found in our series), with a peak in patients with SS (33\%), strongly different from that found in our cohort $(8.6 \%)$ and in 2 other previously published studies $(7.5 \%$ and $9.9 \%)^{9,10}$. Notably, all anti-CCP-positive patients with SS described by Payet had joint involvement, with evidence of synovitis in the great majority $(82 \%)$. This agrees with Atzeni's investigation ${ }^{10}$, which reported a close association between anti-CCP and synovitis in SS. Interestingly, in our cohort, all SS patients with circulating anti-CCP were diagnosed with SS associated with RA. All the anti-CCP-negative patients with SS were classified as primary $\mathrm{SS}$, because they did not fulfill RA classification criteria.

Along with CTD, SS shares clinical and laboratory manifestations with RA, including polyarthritis and high prevalence of rheumatoid factor positivity, making it difficult to differentiate between SS and RA. In agreement with the previously mentioned studies ${ }^{9,10}$ and Payet's investigation, anti-CCP titer was high in all our patients with SS, thereby confirming that anti-CCP levels cannot discriminate between SS and RA.

Importantly, in these studies, the diagnosis of RA has been ruled out in patients with SS by the 1987 American College of Rheumatology classification criteria, with joint erosions as the main target for RA definition. Patients with SS who had bone erosions, indeed, were excluded in Gottenberg's 9 and Atzeni's ${ }^{10}$ evaluations, because they were considered to have RA. Payet found articular erosions in 3 patients with SLE and SSc, but in no patients with SS and polyarthritis.

It should be remembered that a close association between erosions and anti-CCP has been shown not only in $\mathrm{RA}^{11,12}$. These observations raised the question of the diagnostic significance of these autoantibodies in CTD. In this setting, it is noteworthy that a number of anti-CCP-positive patients with RA do not develop joint damage over time ${ }^{13}$. In addition, anti-CCP appear to be more frequently detected in RA patients with associated SS than in those without the syndrome ${ }^{14}$. In this context, the application of the 2010 RA classification criteria in anti-CCP-positive patients with SS included in Payet's cohort and in the other cited studies may allow identification of patients with SS already fulfilling these more recent RA classification criteria, because of high anti-CCP titer and synovitis persistence ${ }^{15}$.

If the association of anti-CCP and RA is a well-established concept, there is also evidence that anti-CCP are closely associated with joint involvement independent of rheumatic condition. The relationship between anti-CCP and joint erosions has also been well documented in RA, and several investigations have been performed to clarify pathogenic mechanisms by which tolerance to citrullinated proteins can be broken and joint inflammation and damage can be triggered in RA. In this context, the finding of anti-CCP in non-RA patients should be interpreted with caution from a clinical point of view, but more importantly, could provide an interesting tool to acquire additional information on the pathogenic role exerted by anti-CCP in inducing joint inflammation and/or damage in these patients.

SARA CATERBI, PhD; ONELIA BISTONI, BSc; ALESSIA ALUNNO, MD; ELENA BARTOLONI, MD; ROBERTO GERLI, MD, Rheumatology Unit, Department of Medicine, University of Perugia, Perugia, Italy. Address correspondence to Prof. R. Gerli, Rheumatology Unit, Department of Medicine, University of Perugia, Via Enrico dal Pozzo snc, I-06122, Perugia, Italy. E-mail: roberto.gerli@unipg.it

\section{REFERENCES}

1. Payet J, Goulvestre C, Bialé L, Avouac J, Wipff J, Job-Deslandre C et al. Anticyclic citrullinated peptide antibodies in rheumatoid and nonrheumatoid rheumatic disorders: experience with 1162 patients. J Rheumatol 2014;41:2395-402.

2. Aggarwal R, Liao K, Nair R, Ringold S, Costenbader KH. Anti-citrullinated peptide antibody assays and their role in the diagnosis of rheumatoid arthritis. Arthritis Rheum 2009;61:1472-83.

3. Fabien N, Olsson NO, Goetz J, Johanet C, Escande A, Bardin N, et al. Prevalence of autoantibodies to cyclic citrullinated peptide in patients with rheumatic diseases other than rheumatoid arthritis: a French multicenter study. Clin Rev Allergy Immunol 2008;34:40-4.

4. Vittecoq O, Incaurgarat B, Jouen-Beades F, Legoedec J, Letourneur $\mathrm{O}$, Rolland D, et al. Autoantibodies recognizing citrullinated rat filaggrin in an ELISA using citrullinated and non-citrullinated recombinant proteins as antigens are highly diagnostic for rheumatoid arthritis. Clin Exp Immunol 2004;135:173-80.

5. Pietrapertosa D, Tolusso B, Gremese E, Papalia MC, Bosello SL, Peluso G, et al. Diagnostic performance of anti-citrullinated peptide antibodies for the diagnosis of rheumatoid arthritis: the relevance of likelihood ratios. Clin Chem Lab Med 2010;48:829-34.

6. Kim DA, Kim TY. Is serum anti-cyclic citrullinated peptide level useful in the diagnosis of rheumatoid arthritis? Clin Chim Acta 2010;413:831-2.

7. Bizzaro N, Tonutti E, Tozzoli R, Villalta D. Analytical and diagnostic characteristics of 11 2nd- and 3rd-generation immunoenzymatic methods for the detection of antibodies to citrullinated proteins. Clin Chem 2007;53:1527-33.

8. Bartoloni E, Alunno A, Bistoni O, Bizzaro N, Migliorini P, Morozzi $\mathrm{G}$, et al. Diagnostic value of anti-mutated citrullinated vimentin in comparison to anti-cyclic citrullinated peptide and anti-viral citrullinated peptide 2 antibodies in rheumatoid arthritis: an Italian multicentric study and review of the literature. Autoimmun Rev 2012;11:815-20.

9. Gottenberg JE, Mignot S, Nicaise-Rolland P, Cohen-Solal J, Aucouturier F, Goetz J, et al. Prevalence of anti-cyclic citrullinated peptide and anti-keratin antibodies in patients with primary Sjögren's syndrome. Ann Rheum Dis 2005;64:114-7.

10. Atzeni F, Sarzi-Puttini P, Lama N, Bonacci E, Bobbio-Pallavicini F, Montecucco C, et al. Anti-cyclic citrullinated peptide antibodies in primary Sjögren syndrome may be associated with non-erosive synovitis. Arthritis Res Ther 2008;10:R51. 
11. Kakumanu P, Sobel ES, Narain S, Li Y, Akaogi J, Yamasaki Y, et al. Citrulline dependence of anti-cyclic citrullinated peptide antibodies in systemic lupus erythematosus as a marker of deforming/erosive arthritis. J Rheumatol 2009;36:2682-90.

12. Zhao Y, Li J, Li XX, Li C, Li L, Li ZG. What can we learn from the presence of anti-cyclic citrullinated peptide antibodies in systemic lupus erythematosus? Joint Bone Spine 2009;76:501-7.

13. Meyer O, Labarre C, Dougados M, Goupille P, Cantagrel A, Dubois $\mathrm{A}$, et al. Anticitrullinated protein/peptide antibody assays in early rheumatoid arthritis for predicting five year radiographic damage. Ann Rheum Dis 2003;62:120-6.
14. Brown LE, Frits ML, Iannaccone CK, Weinblatt ME, Shadick NA, Liao KP. Clinical characteristics of RA patients with secondary SS and association with joint damage. Rheumatology 2014 Oct 13 (E-pub ahead of print).

15. Aletaha D, Neogi T, Silman AJ, Funovits J, Felson DT, Bingham CO 3rd, et al. 2010 rheumatoid arthritis classification criteria: an American College of Rheumatology/European League Against Rheumatism collaborative initiative. Ann Rheum Dis 2010; 69:1580-8.

J Rheumatol 2015;42:6; doi:10.3899/jrheum.141486 